\title{
DESFILIAÇÃO, POLÍTICAS PÚBLICAS E INTERVENÇÃO SOCIAL
}

\author{
DISAFFILIATION, PUBLIC POLICY AND SOCIAL POLICY
}

\author{
Clara Cruz Santos ${ }^{1}$ \\ Helena Neves Almeida ${ }^{2}$
}

\begin{abstract}
RESUMO
A sociedade contemporânea, também designada sociedade do conhecimento, é paradoxal. Nela convivem, e por vezes se confrontam, a potência ouro e a potência desespero, ladeadas por uma aparente igualdade de oportunidades no acesso à educação, ao direito, ao trabalho. Nessa sociedade, a pobreza, a fome, o desemprego, a vulnerabilidade, o risco e a incerteza cruzam-se, e raramente se encontram, com os elevados índices de rendimento econômico, o exercício do poder oriundo da posição social aliada ao capital financeiro, os luxuosos e elevados padrões de vida e de consumo daqueles que, sendo em número cada vez menor, mais possuem. As políticas sociais em execução têm tido um papel remediativo e não "curativo" dos processos de exclusão social (CONTI, 2010), potenciando um "ciclo vicioso" tanto do aumento da despesa pública, como da expansão da pobreza e da exclusão social, criando espaços de vulnerabilidade nos quais o cidadão apresenta evidentes traços de desgaste, inibindo sua participação na manutenção ou na mudança do sistema. O grande déficit de integração social precisa ser estudado e reavaliado cruzando evidências discursivas, vulnerabilidades reais e processos de construção do fatalismo funcional presentes na sociedade atual (CONTI, 2010).
\end{abstract}

Palavras-chave: Paradoxos sociais. Desfiliação social. Políticas públicas.

\begin{abstract}
Contemporary society, also referred as the knowledge society is paradoxical. Coexist in it, and sometimes clash, gold power and despair, sided by an apparent equality of opportunity in access to education, right to work, scientific and technological innovation platforms; in it, poverty, hunger, unemployment, vulnerability, risk and uncertainty cross each other, and rarely meet, with the high indices of economic performance, power is exercised from the social standing combined with the finance capital, the luxurious and high standards of living and consumption of those who are dwindling in number, possess more. The social policies implemented have played in the social exclusion processes a "remediation" and not "healing" role. This, causes a "vicious cycle" of both increased public spending, as the expansion of poverty and social exclusion, creating vulnerability spaces where the citizen is, already, showing evident wear and tear traces, inhibiting their active participation in maintaining or changing the system. The large social integration deficit needs to be studied and re-evaluated crossing discursive evidence, actual vulnerabilities and construction processes of functional fatalism in today society (Conti, 2010).
\end{abstract}

Keywords: Social paradoxes. Social disaffiliation. Public policies.

\footnotetext{
${ }^{1}$ Doutorada em Serviço Social pela Universidade Católica Portuguesa. Docente do Curso Superior de Serviço Social na Faculdade de Psicologia e Ciências de Educação da Universidade de Coimbra (Portugal). Email: claracruzsantos@gmail.com

${ }^{2}$ PhD em Trabalho Social pela Universidade de Fribourg, Suisse. Docente da Universidade de Coimbra (Portugal). Email: helena.almeida03@gmail.com
} 


\section{Introdução}

A reflexão profunda e substancial sobre os pressupostos dos modelos de proteção social na lógica actual de redimensionamento de seus sistemas, diante das novas formas de pobreza e do desajuste das políticas sociais, possui, antes de mais, um caráter ideológico e político. A tentação de reduzir um tal debate a uma simples dimensão econômico-financeira obscurece a verdadeira discussão sobre os fundamentos e nega a necessidade de conceitualizar fórmulas inovadoras de gestão da solidariedade social. Neste contexto, as tentativas de redefinição da relação com o todo, que se evidenciam nas agendas político-sociais nacionais e europeias, merecem uma análise mais cuidada, nomeadamente no que diz respeito à reinterpretação da solidariedade e do papel do Estado e sua relação com os novos assistidos da proteção social, marcadamente rotulados como os novos pobres do século XXI.

As relações sociais que condicionam - ou, em grande de parte, determinam - as trajetórias sociais destes cidadãos, têm em conta não só uma perspectiva coletiva dos mesmos (isto é, interessa não só o olhar dos "outros sobre os mesmos"), mas cruzaram dados e significados assumidos pelos sujeitos, nomeadamente em sua relação com o Estado e uma sociedade inundada de paradoxalidade no que respeita à relação entre classes e as desigualdades sociais daqui inerentes. De acordo com relatório da Cáritas Portuguesa (2013, p.3): "Portugal is the EU country with the highest income distribution inequality - the share earned by the range of 20 percent of the population with the highest income is more than 7 times higher than received by 20 percent of the population with the lowest income".

Em Portugal convivem, e por vezes se confrontam, a potência ouro e a potência desespero com uma aparente igualdade de oportunidades que, na realidade, é inexistente, devido à desigualdade de distribuição dos rendimentos e consequente acessibilidade a mecanismos de inserção e qualidade de vida das populações. O programa de Emergência Social, sendo necessário dada a aviltante desigualdade de direitos e oportunidades, expressa não apenas a contingência da situação de crise que vivemos decorrente do déficit orçamental e da política neoliberal que foi posta em prática após a intervenção da
Troika (Comissão Europeia, Banco Europeu e Fundo Monetário Internacional), mas também a desconstrução do Modelo Social Europeu. Assistimos sua desconfiguração pela via da subordinação do social ao econômico. A noção de Direitos Humanos é uma questão fundamental das sociedades atuais, embora sua permanente referência no discurso minimalista e midiático das agendas político-ideológicas não passa de mais uma metanarrativa em desagregação, ou de um conteúdo excessivamente impreciso e manipulável para ser tomado em consideração. Desta forma, é importante compreender quais são os contextos e as características atribuídas pelos sujeitos aos seus processos de exclusão/pobreza numa lógica quase de retrato social e, por outro lado, compreender o papel do Estado nestes novos movimentos. Isto é, o desafio constitui não apenas em identificar os programas sociais e as várias iniciativas locais em que os sujeitos estão ou estiveram envolvidos, mas também desvendar as possibilidades e os limites neles contidos para se constituírem como alternativas emancipadoras ou elementos reprodutores da privação e da ausência de cidadania.

Nesta senda, o presente artigo centra-se na clarificação conceitual, tendo por método uma pesquisa bibliográfica e documental do processo de desfiliação social e as iniciativas politicas e governamentais levadas a cabo no contexto atual, que designamos como um contexto de vulnerabilidades e fatalismo funcional, propondo-se contribuir para a análise do caráter paradoxal das políticas públicas.

\section{Da desfiliação social}

A utilização do termo "desfiliação social" associada a processos extremos de exclusão social, apesar de recente em Portugal, advém do fenômeno descrito por Castel (1977, p.56), sentido em finais do século XX como “"[...] uma ruptura de pertença, de vínculos societais [...] O desafiliado (excluído) é aquele, cuja trajetória é feita de uma série de rupturas com relação a estados de equilíbrio anteriores, mais ou menos estáveis, ou instáveis [...]".

Para Paugam (2000), a desfiliação social não é apenas a fase "terminal" de um processo, mas o próprio processo de “desqualificação social". De fato, "a partir de certos níveis de diferenciação negativa, as pessoas, as famílias e os grupos encontram-se 
excluídos dos padrões de vida e dos mecanismos de participação tidos como minimamente aceitáveis em cada sociedade concreta." (CAPUCHA, 2005, p.70). Não se trata apenas de um processo de desvinculação social devido à existência (progressiva ou abrupta) de situações de precariedade (a maior parte das vezes associadas à exclusão do mercado de trabalho), mas, igualmente, a uma perda de identidade social pela incapacidade do cidadão em aceder a patamares mínimos de integração socioeconômica, resultando no enfraquecimento das redes de sociabilidade e na incapacidade de obtenção de suporte social por meio de redes informais.

Falamos de um espaço simbólico de difícil intervenção uma vez que estes cidadãos (não pertencentes, em sua maioria, a uma pobreza tradicional e transgeracional) possuem características que os colocam num "patamar intermediário" de análise social. Isto é, podem ser observados por duas perspectivas (GARCIA, 2006): (i) desvinculação diante de uma determinada situação concreta que em Portugal se encontra grandemente influenciada pela deterioração do mercado de trabalho enquanto eixo central dos processos de inclusão social (YÉPEZ DE CASTILHO, 1994; CASTEL, 1998), bem como pela consequência das medidas de austeridade governamentais no cumprimento do programa "Troika" para redução do déficit nacional diante da União Europeia, e, (ii) desvinculação como retrato de uma condição em contraposição ao caráter processual deste fenômeno. Nesta dimensão exemplificamos os trabalhos de Castel (1998) que defende a distinção entre as diferentes etapas do processo de desfiliação em que a primeira etapa seria a de integração social eficaz, a segunda, de vulnerabilidade caracterizada pela precariedade do trabalho e a fragilidade dos apoios proporcionados pelas relações familiares e sociais e uma terceira fase de exclusão. Para este autor, a exclusão social primária conducente a uma forma de desfiliação inicia-se com a perda ou diminuição dos vínculos sociais antes de sua ruptura.

Ora, este processo é claramente visível na análise da situação social portuguesa. Portugal vivencia um conturbado período de precariedade econômica e social. A atual crise financeira, ao atingir fortemente a classe média, colocou milhares de cidadãos em patamares de existência insustentáveis, em que a vulnerabilidade e a precariedade ganham espaço e assumem o controle de suas vidas.

Em 25 de Maio de 2012, no Barômetro das Crises (CES, 2012) podem ler-se os seguintes resultados:

A Taxa de desemprego em Maio de 2012 é de 14,9\%, o que corresponde a 819.3 mil pessoas (num país com um total de 10 milhões de habitantes). Se forem tidos em conta os inativos desencorajados e os inativos disponíveis, o desemprego real é muito superior. O número de inativos desencorajados é de 90.8 mil pessoas, tendo aumentado $50.6 \%$ em relação ao mesmo trimestre do ano anterior. O número de inativos disponível é de 202.1 mil pessoas, tendo aumentado $40.5 \%$ em relação ao $1^{\circ}$ trimestre de 2011 (CES, 2012, p.1). ${ }^{3}$

$\mathrm{O}$ aumento de precariedade social em Portugal não se encontra somente relacionado com o fator emprego, ele observa-se igualmente no aumento de medidas de austeridade relacionadas com cortes salariais (tendo maior impacto na classe média), com o aumento exponencial de impostos e o aumento do custo de bens essenciais à garantia de qualidade de vida e de subsistência, como bens alimentares, energia, saúde, educação e habitação. A par destas medidas assiste-se a um recuo do Estado no que diz respeito à proteção social, contribuindo para o aumento das desigualdades sociais e de situações de pobreza extrema, isto é, o aumento de cidadãos que vivem abaixo dos níveis de sobrevivência física e social, e daqueles que, tendo pertencido à classe média, encontram-se em risco de pobreza.

O reflexo das medidas de austeridade nas condições de vida dos portugueses tem sido devastador. No jornal "Destaque" do Instituto Nacional de Estatística sobre "Rendimentos e Condições de Vida", de 13 de julho de 2012, o risco de pobreza das famílias portuguesas situava-se nos $18 \%$, sendo a média europeia de $16,4 \%$. Por outro lado, as medidas de proteção social sofreram igualmente cortes orçamentais e, desta forma, uma maior dificuldade ao seu acesso

\footnotetext{
${ }^{3}$ Por Inativo disponível entende-se todo o cidadão com idade mínima de 15 anos que, pretendendo trabalhar, não tinha emprego e não tinha realizado quaisquer diligências para o encontrar. Por Inativo Desencorajado, entende-se todo o cidadão com idade mínima de 15 anos, desempregado, não tendo realizado qualquer diligência para encontrar emprego, por sentir que não tinha as condições mínimas para o obter (idade, escolaridade, outras condições de competitividade), nem saber como procurar, ou sentir que nem valia a pena fazê-lo (desânimo).
} 
por parte da população. De acordo com o Instituto Nacional de Estatística (2012), o impacto das transferências sociais para diminuição do risco de pobreza obteve um efeito diminuto, pelo que assistimos a rupturas familiares graves.

Em Portugal, o acesso a direitos sociais e a defesa por sua continuidade é uma questão fundamental do âmbito dos direitos de cidadania, isto é, configura-se como uma questão duplamente individual e coletiva. Individual, na medida em que para cada cidadão o aumento das desigualdades sociais é percebido como uma forma de injustiça social e de ataque aos direitos adquiridos e a condições de vida com dignidade. Coletivo, porque a consciência crítica nacional se encontra comprometida com as consequências e o sentimento de injustiça social é entendido como uma afronta ao regime democrático em vigor, que impede uma participação cívica em paridade, contribuindo para o aumento de fraturas sociais graves, das quais as situações de pobreza e exclusão social são uma de suas faces mais visíveis.

Os "filhos" desta realidade não são só (mas também) as famílias e/ou cidadãos mais associados a uma pobreza transgeracional ou tradicional. Nestes observam-se menos os fenômenos colaterais da exclusão social, e mais modos de vida usualmente rurais ou de zonas de periferia urbana com rendimentos econômicos baixos, déficits educativos e qualificações profissionais não compatíveis com as exigências do mercado de trabalho, sendo tradicionalmente usuários frequentes dos esquemas e medidas de proteção social. Assiste-se, concomitantemente, à emergência de uma nova pobreza associada ao "valor-trabalho" que, ao perdê-lo ou ao verem seus rendimentos drasticamente reduzidos, não conseguem sustentar compromissos assumidos.

Assim, os processos de desfiliação atuais estendem-se aos setores formais, nos quais os trabalhadores antes considerados incluídos assumem, agora, um novo estatuto, não de situações extremas de inclusão ou exclusão (conceito tradicional de pobreza), mas de situações intermédias, pelo conceito de vulnerabilidade social aplicado ao mundo do trabalho e à perda de direitos sociais. As situações intermédias refletem-se quer nas dinâmicas de desigualdade e na mobilidade (ascendente ou descente) que determinados grupos sociais estarão sujeitos (Garcia, 2006), quer nos cidadão pertencentes a uma classe média que luta para manter o seu padrão de inserção e bem estar.

Em consequência confrontamo-nos com o risco da falta de coesão societária. Esta está estritamente relacionada com a sua capacidade de fazer face aos múltiplos riscos derivados quer do próprio ambiente social e económico, quer das organizações e medidas sociais públicas. No entanto, as medidas de austeridade, as necessidades de novas medidas sociais e sua legitimidade complexificam o sistema de proteção social atual e, consequentemente, a capacidade dos cidadãos a ele acederem, podendo aumentar o perigo de riscos internos e externos ao sistema, em detrimento de medidas securizantes necessárias e estratégias de relação do sujeito com os sistemas de proteção social.

O presente contexto enquadra-se na visão de Messu (1994), em que uma situação de "não-integração" é, igualmente, (além dos movimentos sociais e políticos de caráter macro) uma situação vivida por indivíduos com capacidade de realizar um julgamento sobre a mesma e agir em conformidade. É neste contexto que a inquietude social assume contornos de grandeza crescente. $\mathrm{O}$ sentimento de incerteza, o medo quanto ao futuro, o aumento exponencial da nova pobreza e a falta de confiança nos dirigentes políticos que representam os cidadãos são visíveis no aumento de movimentos sociais e de manifestações públicas de contestação contra os atos governamentais nacionais e os processos de regulação econômica europeia.

\section{Da paradoxalidade das políticas públicas}

A atual crise econômica e social associada, em Portugal, ao fim do Estado-Providência tem assistido a propostas resolutivas relacionadas com o discurso neoliberal, sendo um de seus principais argumentos o fato de o Estado-Providência (assente no contrato social Rousseauniano ${ }^{4}$ "induzir a situações de dependência (...) perpetuação de situações de exclusão social e pobreza em que famílias e cidadãos haviam vivido não do rendimento do seu trabalho, mas de apoios sociais do Estado" (SILVA, 2013, p. 36). Tais argumentos são, logicamente, controversos, na medida em que nos parece derivar de uma leitura liberal

\footnotetext{
${ }^{4}$ Contrato Social defendido por Rousseau (2007).
} 
e economicista da questão, em que o autor se refere ao contrato social por trás do Estado Providência (aliança entre o capital e o trabalho na criação do capital social sustentador das medidas de proteção social) como "fruto de um compromisso intergeracional, condicionado à existência de uma situação económico-financeira e politica que os sustente. $\mathrm{Na}$ ausência destas condições, falar em "direitos sociais adquiridos" (idem; ibidem) é, nesta óptica, um contra senso.

Os direitos sociais em Portugal são jovens, como é jovem nossa democracia cujo produto mais visível da Revolução de 1974 se consubstancia na Constituição de 1977, considerada como a "lei suprema do nosso país" (CRP, 1977) e na qual se encontram consagrados os direitos fundamentais dos cidadãos, que contemplam o direito à saúde, educação, habitação, ao trabalho, à participação, entre outros. Estes direitos não se reduzem a um pacto econômico, mas fundamentam-se num Estado de princípio e com valores democráticos "no respeito e defesa da dignidade humana" (CRP, 1977), pilares fundamentais das sociedades modernas. Estes sistemas são geradores de igualdades sociais e podem ser enquadrados em quatro processos (THERBON, 2006 apud COSTA, 2012) classificados pelo autor de acordo com critérios relacionados com: 1) a relação entre o Estado e o Mercado; 2) a forma de atuação do Estado perante as políticas sociais e os modelos de proteção social; 3) a "idade" democrática dos países e 4) caraterísticas relacionadas com a organização e estratificação social. Nesta senda, Estados-Providência diferenciados surgem em diferentes países com práticas políticas e sociais próprias.

Não é nossa intenção sintetizar os vários modelos dos Estados-Providência, mas importa, de fato, chamar a atenção que os países que mais têm sido afetados pela atual recessão econômica se encontram no Sul da Europa (Portugal, Espanha, Grécia e Itália). São Estados Sociais recentes, com esquemas de proteção social anteriores relacionados com práticas caritativas de organizações civis e religiosas e com uma herança política de regimes autoritários.

O desafio atual reside na transformação das políticas públicas, em particular na redefinição do papel e da articulação do Estado, do mercado, das organizações do terceiro setor e dos cidadãos na reconstituição da ação pública e do contrato social da atualidade. De acordo com Santos (2001), o contrato social é a metáfora fundadora da racionalidade social e política da modernidade ocidental. Assenta em critérios de inclusão que são, igualmente, critérios de exclusão. Visa criar um paradigma sociopolítico que produza quatro bens públicos: (1) legitimidade de governação; (2) bem-estar econômico e social; (3) (in)segurança e (4) identidade coletiva. Não se trata apenas de garantir a sustentabilidade do capital social fundamental para sobrevivência dos esquemas de proteção social, de acordo com o pensamento keynesiano, mas o de garantir segurança aos cidadãos. A segurança funda-se na confiança coletiva que os atores sociais têm que sentir na figura do Estado e que passa pela reconfiguração da relação entre os cidadãos e os sistemas de proteção social.

A eficácia das políticas sociais e das medidas de combate à exclusão e à desfiliação social encontra-se relacionada com a necessidade de elaboração de políticas públicas mais amplas, cujas metas são preventivas e não apenas reparadoras.

[...] parece mais fácil e realista intervir sobre problemas relativamente limitados que representam os excluídos [...], que controlar ou tentar controlar os processos que desencadeiam tal exclusão. Ocupar-se das consequências destes processos, [...] mobilizar basicamente respostas técnicas (ainda que não sejam fáceis de encontrar), mas o domínio do processo exigirá um tratamento político, no sentido da política global."(KARSZ, 2004, p.61).

Torna-se necessário alterar a perspectiva de avaliar e intervir nos problemas e conflitos sociais, abrindo-se a possibilidade não apenas de prevenir sua emergência mas de agir no sentido de diminuir sua escala, estimulando as relações colaborativas e cooperativas, dando corpo à concepção de provenção. Burton (1990), referindo este conceito no campo da gestão dos conflitos, salienta que provenção significa deduzir, a partir de uma explicação adequada do fenômeno, incluindo suas dimensões humanas, não apenas as condições subjacentes e as mudanças estruturais requeridas para superar a situação, mas "a promoção de circunstâncias que criam relações cooperativas" (BURTON, 1990, p.3, apud TORREMORELL, 2003, p.38). O combate à desigualdade implica, pois, políticas em que a transformação social está presente, acarretando a melhoria das relações humanas - viver, estar 
e relacionar-se melhor, ou seja, uma maior proximidade física dos serviços e das instituições e, ainda, a remoção de barreiras simbólicas interpostas entre o cidadão e os agentes de administração, de modo a promover uma verdadeira participação e o potencial de intervenção em defesa dos interesses próprios. É pois de políticas de emporwerment (FRIEDMANN, 1996, apud CAPUCHA, 2005, p.250) que precisamos. Neste sentido, é fundamental repensar os modelos de intervenção utilizados em nível social e trabalhar uma consciência crítica sobre as potencialidades e os limites das ações que se desenvolvem neste domínio. Neste contexto, a construção de alternativas sociais ganha lugar de destaque, ultrapassando a ideia de fatalismo social, subjacente à inércia e ao baixo nível de consciência crítica e cidadã.Importa igualmente desvendar as possibilidades e os limites contidos na relação entre a pessoa do Estado e os cidadãos, no sentido de se constituírem como alternativas emancipadoras ou elementos reprodutores da privação e da ausência de cidadania. Esta última alternativa já não é viável, apesar de presente. Segundo o modelo de Demaziére (1995), os factores de vulnerabilidade dos grupos sociais mais fragilizados resultam da interação entre factores de vulnerabilidade extrínseca, que se reportam aos espaços de risco social e aos efeitos do contexto, isto é, os efeitos potenciadores ou bloqueadores da emancipação social do sujeito e, ainda, fatores de vulnerabilidade intrínseca, isto é, todo o conjunto de características internas ao sujeito, grupo ou família que potenciam, por sua natureza, o aumento de precariedade e desânimo e sua interpolação num movimento contínuo de inclusão/ exclusão social de difícil ruptura. Atualmente, impõese uma intervenção em função de uma diversidade e complexidade de fatores, em parceria e assente numa lógica de conceitos transversais. Essa lógica obriga a salvaguardar, desde já, o comprometimento real de todos os atores sociais em proximidade com o Governo Central. É imprescindível desenvolver programas e mecanismos que incorporem a participação e estimulem a interação com a sociedade e que deem prioridade à autonomia e ao empoderamento (empowerment) dos sujeitos atendidos pelas políticas públicas. "Não se trata de participação residual, formal ou pontual, mas de participação efetiva, que privilegie relações horizontais e que considere os beneficiários parceiros reais dos programas, que assumem compromissos, responsabilidades, tarefas compartilhadas." (CARNEIRO, 2005, p.19). O objetivo das intervenções passa pelo fortalecimento de capacidades e competências, pela mobilização dos cidadãos e pelo desenvolvimento de iniciativas que favoreçam o incremento do capital social, ou, nas palavras do autor: "(...) fortalecer os ativos existentes nas comunidades, a partir do mapeamento dos recursos reais." (Idem).

Estamos perante novas formas de governação que interagem entre si. Aos atores tradicionais, como o Estado, vieram juntar-se novos actores e, consequentemente, confrontação e encontro de saberes (COSTA, 2003). A política sinérgica, ou seja, a contribuição ativa e concertada dos diferentes agentes, "que nos conduzirá a maiores e mais produtivos resultados" (COVEY E ENGLAND, 2012, p. 28), abre uma nova dimensão na proteção social possibilitando o crescimento, a transformação mútua e o aproveitamento racional das respectivas oportunidades. Deste modo, ao mercado são reenviadas as procuras salváveis; é a instância individualizadora, capaz de responder às preferências dos cidadãos, por meio do incremento de diversas formas de organização, e potencializando ações qualitativamente diversificadas. Do mesmo modo, as iniciativas privadas sem fins lucrativos (enquadrando-se na chamada economia solidária) passam a ser reconhecidas como parceiras na produção e distribuição de serviços públicos.

\section{Considerações finais}

O novo modelo produtivo e as orientações econômicas e sociais das políticas públicas com caráter cumulativo e não distributivo, têm contribuído para o aumento de assimetrias sociais e de novas formas de exclusão social que, em última instância, traduzem o que designamos por processos de desfiliação social. A crescente incapacidade de dar respostas sustentáveis, capazes de se concretizarem numa ruptura com os mecanismos de vulnerabilidade e precariedade social tem causado fraturas sociais com um forte impacto na vida de milhares de portugueses. Sua face invisível é o que as torna tão relevantes e preocupantes diante da nova ordem social. A verdade é que as novas situações de pobreza e os fenômenos de desfiliação social possuem um caráter subjetivo 
que, embora sentido individualmente, possui um efeito multiplicador na organização social atual.

As rupturas familiares, o sobreendividamento, a perda da habitação em prol da banca, a "fome escondida", a diminuição da sociabilidade, enfim, todos os mecanismos de perda identitária do sujeito têm repercussões na manutenção da coesão social, nas redes de reciprocidade e solidariedade. Significa, pois, que mais do que os aspectos estruturais e materiais relacionados com a pobreza, estão igualmente envolvidos valores, condutas e atitudes que acabam por reforçar a manutenção de situações de vulnerabilidade e desfiliação.

Fernanda Rodrigues (2002) realça o caráter descontínuo e enfraquecido das medidas públicas e respostas sociais portuguesas em que o sistema de proteção social é pontuado "pelas dificuldades de transitar de uma prática de ajuda para uma estratégia de política social. O consenso criado sobre a assistência social como campo de possibilidades não tem encontrado equivalente num percurso estratégico de sua afirmação no campo da política social” (RODRIGUES, 2002, p. 294).

Assim, mais do que os aspectos economicos relacionados com os processos redistributivos, falha nas políticas públicas uma estratégia de participação, compensação e emancipação dos cidadãos. As ajudas existentes são pontuais e visam uma lógica de homogeneização dos problemas e tipificação de públicos e respostas, em prol de uma valorização da singularidade e equidade. Neste sentido, a dimensão econômica do terceiro setor revela-se como um importante recurso a explorar, pela possibilidade que oferece de construção de respostas socioeconômicas inovadoras, valorizando o potencial de agentes sem fins lucrativos na produção de bens e serviços orientados para o bem comum e a reconstituição e consolidação de coesão social. Aqui, a construção de alternativas adquire sentidos diversos, tão distintos quantos os atores envolvidos e os contextos sociais, políticos e econômicos considerados. Sede de diversos patamares de realização (pessoal, familiar, social, profissional, econômico e político), as alternativas sociais vão-se construindo e edificando numa simbiose entre a satisfação das necessidades e a construção de uma sociedade mais igualitária e justa. As políticas inovadoras geram e sustentam sinergias que se traduzem em participação efetiva e consequente, em nível individual e colectivo.

O "contrato social" defendido por Rousseau, ao considerar que todos os homens nascem livres e iguais, sendo o Estado um objeto de um contrato no qual os indivíduos não renunciam aos seus direitos naturais, mas, ao contrário, entram em acordo para a proteção desses direitos, tem que ser revitalizado em detrimento da visão neoliberal das políticas sociais atuais que, ao atuarem sobre os sintomas de mal-estar social, são ineficazes na resolução dos problemas sociais complexos e multidimensionais.

\section{Bibliografia}

ALBUQUERQUE, C. Acompanhamento social, capacitação e responsabilização. A "subjetivação" da intervenção social in SANTOS, C., ALBUQUERQUE, C. \& ALMEIDA H.( orgs). Serviço Social: Desafios e Mutações Atuais. Coimbra: Imprensa da Universidade de Coimbra, 2013.

AMARO, R. A exclusão social hoje. Lisboa: Cadernos do ISTA:Instituto de São Tomás de Aquino, 1999.

ARAÚJO, H. Nós e os Outros: A exclusão em Portugal e na Europa. Lisboa: Gradiva publicações, 1998.

BAPTISTA, A. A investigação em serviço social. São Paulo: Veras, 2001.

BURAWOY, M. For public sociology. American sociological review, v. 70, fev. 2005, p. 4-28.

BURTOB, J. Conflict: resolution and srovention. New York : St. Martin's Press, Inc., 1990.

CAPUCHA, L. Desafios da pobreza. Oeiras: Celta Editora, 2005.

CARNEIRO, C. Concepções de pobreza e suas implicações para o desenho de programas voltados para famílias em situação de vulnerabilidade social. Brasília. Anais. XII Congresso Brasileiro de Sociologia, 2005.

CASTEL, R. A dinâmica dos processos de marginalização: da vulnerabilidade à "desfiliação". Cadernos CRH, no 26 e 27, 1997, p. 19-40.

As armadilhas da exclusão. In: Desigualdade e a questão social. São Paulo: EDUC, 1997, p. 15-48.

CASTELLS, M. Networks of outrage and hope: social movements in the internet age. Cambridge: Polity Press, 2012.

CELADE. Vulnerabilidad social en América latina y el Caribe. Área de Población y Desarrollo. Santiago de Chile: LC/DEM/R.298, 1999.

CENTRO DE ESTUDOS SOCIAIS (CES). O Barómetro das Crises. In: Observatório das Crises e das alternativas, Vol 
1, 25.05.2012.Coimbra: Centro de Estudos Sociais (CES). Universidade de Coimbra, 2012.

CLAVEL, G. (2004), A sociedade da exclusão: compreendêla para dela sair. Porto: Porto Editora.

CONTI, D. Uma abordagem do tema: Gestão Social. Revista Iluminart, Volume 1, $\mathrm{n}^{\circ}$ 4; Serãozinho: IPSP, abril 2010, p $1-10$.

COSTA, A. Desigualdades sociais contemporâneas. Lisboa: Editora Mundos Sociais, 2012.

Exclusões sociais. In: Cadernos Democráticos n. ${ }^{\circ}$ 2, Lisboa: Fundação Calouste Gulbenkiab, 1998.

COSTA, A. et al. Um olhar sobre a pobreza: vulnerabilidade e exclusão social no Portugal contemporâneo. Lisboa: Gradiva, 2009.

COSTA, S. A cegueira do Estado face às Famílias. Coimbra: Centro de Estudos Sociais, 2003.

COVEY, S. \& ENGLAND, B. La $3^{\mathbf{a}}$ Alternativa. Para resolver los problemas más dificiles de la vida. Barcelona: Paidós, 2012.

DANE, C. Travailler avec les quartiers en difficulté. Paris: Dunod, 2005.

DEMAZIÈRE, D. La sociologie du Chômage. Paris: La Découverte, 1995.

DIESE. Aspectos conceituais da vulnerabilidade social. Brasília: Convênio MTE/SPPE/CODEFAT - N. 075/2005, 2007.

FANGUEIRO, C. (coord.) Tipificação das situações de exclusão em Portugal Continental. Lisboa: Instituto de Segurança Social, 2005.

GARCIA, B. La situación laboral precária: marcos conceituales e ejes analíticos pertinente. Revista Trabajo, ano 2, nº 3, Julio-deciembre, México: OIT, 2006.

HESPANHA, P. Políticas sociais: Novas abordagens, novos desafios, 2008. Disponível em:<//http://www.google. com/url? sa $=$ t\&rct=j\&q=repensar $\% 20$ os $\% 20$ modelos $\% 20$ de $\% 20$ interven $\%$ C3\%A7ao $\% 20$ com $\% 20$ pobres $\% 20 \mathrm{e} \% 20$ exclu $\%$ C3 $\%$ ADdos \&source $=$ web $\&$ cd $=3 \&$ cad $=$ rja\&ved $=0$ CDUQFjAC\&url=http $\% 3 \mathrm{~A} \% 2 \mathrm{~F} \% 2 \mathrm{Fwww}$.ces.uc.pt $\% 2 \mathrm{Fm}$ yces $\% 2$ FUserFiles\%2Flivros\%2F191_Confere_ncia_PH rev.doc\&ei=pxnFUODeEcHQhAfBo4DACQ\&usg=AFQj CNEdojB2s43J8Y-9xtJQUPH5UF9geg>. Acesso em 28 de Abril de 2013.

INSTITUTO NACIONAL DE ESTATÍSTICA. Rendimentos e condições de vida. Jornal "O Destaque". Lisboa: INE, 2012.

KARSZ, S. La exclusión: bordeando sus fronteras, definiciones y matices. Barcelona: Gedisa editora, 2004.
KATZTMAN, R. Seducidos y abandonados: el aislamiento social de los pobres urbanos.Revista dela CEPAL, Santiago do Chile, n.75, 2001, p.171-189.

LEAHY, A; HEALY, S; \& MURPHY, M. The impact of the european crisis: a study of the impact of the crisis and austerity on people with special focus on Greece; Ireland; Italy, Portugal and Spain. Social Justice Ireland (2013) (org.) Caritas Europa: Caritas Report, 2013.

LIND, M. The next american nation: the new nationalism and the fourth. New York: The Free Press, 1995.

MARTINEZ, J. Migración internacional de jóvenes latinoamericanos $\mathbf{y}$ caribeños: protagonismo $\mathrm{y}$ vulnerabilidad. Santiago de Chile: CEPAL-CELADE. LC/ L1407/Corr.1-P, 2000.

MESSU, M. O Estatuto e Identidades dos Assistidos Sociais. In: Soulet in H (1994). Sobre a Não Integração. Suisse: ÉditionsUniversitairesFribourg (Dir.), De la non-intégration. Suisse: ÉditionsUniversitairesFribourg, 1994.

MIZRAHI e GARCIA, C. A capacidade de estar só: um contraponto winnicottiano ao ideal contemporâneo de autonomia absoluta. (2007). Disponível em: $<$ http://www. pucminas.br/imagedb/documento/DOC_DSC_NOME ARQUI20080521145831.pdf $>$. Acesso em: 28 de Abril de2013

PAUGAN, S. A desqualificação social. Um estudo sobre a nova pobreza. Coimbra: Edições Quarteto, 2000.

RODRIGUES, F. Assistência Social: uma política reticente em tempo de globalização. In: HESPANHA, P e CARAPINHEIRO, G. (Orgs.). Risco social e incerteza: pode o Estado Social recuar mais? Porto: Edições Afrontamento, 2002, p. 265-300.

RODRIGUES, J. Vulnerabilidad demográfica: una faceta de las desventajas sociales. Santiago de Chile: CEPALCELADE. LC/L.1422-P., 2000.

ROUSSEAU, J. Do contrato social. Brasília: Edições Edijur, 2007.

RUIVO, F. Poder local e exclusão social. Coimbra: Quarteto, 2000.

SANTOS, B. A nova questão social. In: SANTOS, B. S. A cor do tempo quando foge. Crónicas 1985-2000. Porto: Edições Afrontamento, 2001.

SANTOS, B. Jornal Diário de Noticias Online - 2011-01-02.

Disponível em: <http://www.dn.pt/inicio/portugal/

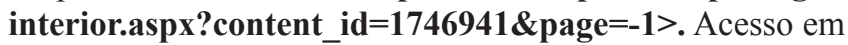
07 de Abril de 2013.

SANTOS, C.; NUNES, V. Desafios da Gestão Social no Serviço Social. In: SANTOS, C., ALBUQUERQUE, C.; ALMEIDA, H. (Orgs.). Serviço Social: desafios e mutações atuais. Coimbra: Imprensa da Universidade de Coimbra, 2013. 
SERRANO, G.; GERRANO, C.; MALO G. ; Rodríguez, C. Un intento de medición dela vulnerabilidad ante la exclusión social. Unidad de Políticas Comparadas (CSIC). Documento de trabajo 00-13. España, 1998.

SILVA, M. Reflexões sobre a questão da proteção social: uma leitura da obra de Robert Castel. (2012). Disponível em: $<$ http://revistaaskesis.files.wordpress.com/2012/04/revistaaskesis-artigo04_p64-81.pdf $>$. Acesso em 28 de Abril de 2013.

SILVA; F. O futuro do estado social. Lisboa: Fundação Francisco Manuel dos Santos, 2013.

THERBON, G. (Org.). Inequalities of the world. New theoretical frameworks, multiple empirical approaches. Londres: Verso, 2006, 332p.

TORRADO, S.; RAFAEL, R. Clases sociales, familia y comportamentos. Urbanos y Regionales. Buenos Aires, Argentina, 1998.

TORREMORELL, M. Cultura de mediação e mudança social. Porto: Porto Editora, 2008.

TOURAINE, A. A sociologia pública e o fim da sociedade. Caderno CRH, Salvador, v. 22, n. 56, p. 245-254, maio/ ago., 2009.

XIBERRAS, M. As teorias da exclusão social. In: Epistemologia e sociedade. Lisboa, Instituto Piaget, 1993.

Recebido em 26 de junho de 2013 Aceito em 10 de outubro de 2013 